\section{Argentinians regroup}

SIR - With the coming of democracy in Argentina, Argentine research workers have organized their professional association with the aim of "building a science and technology engaged with the reality of the country and contributing to its effective independence and sovereignty". In the past, a similar society functioned for researchers of the CONICET (Consejo Nacional de Investigaciones Científicas y Técnicas) but this was dissolved in 1974 and the members of the board of directors were prosecuted and dismissed from their jobs.

The new association, Asociación Argentina de Investigadores Científicos y Tecnológicos (AADICYT), is open to researchers from all disciplines belonging to universities, institutes, public or private enterprises, CONICET, and so on, and its membership covers all categories of investigators, including new fellows.

The president is Dr Enrique Segura, head of a neurobiology research laboratory of CONICET, and the two vice-presidents are Guillermo Dussel, a physicist at the National Commission of Atomic Energy, and Alberto Solari, professor of the Faculty of Medical Sciences. The secretary is Celina Lértora Mendoza, a philosopher, and the treasurer is Osvaldo Gosman, a mathematician and professor of the University of Belgrano.

The first objectives of the society are directed towards reinstating scientists and professional people who have been dismissed for political or discriminative reasons, whether still in this country or abroad. Also, to appeal to all Argentine investigators who are settled permanently in other countries to collaborate in this effort for the recovery and development of science and technology in Argentina. Various forms of collaboration are suggested: to accept fellows from Argentina in their institutions; to give courses and counselling in Argentina; to engage foreign institutes in cooperative programmes with similar institutions from Argentina. AADICYT is also asking that the authorities in science and technology accept delegates from our association in committees dealing with the institutional organization of science, with the investigation of irregularities, with mechanisms for the democratic participation of the researchers, and with a bylaw of rights and duties of research workers.

The address of AADICYT is given below. Our representative in Europe is Mariano Levin, Institut de Pathologie Moleculaire, 24 rue du Faubourg Sr. Jacques, Paris XIV, France. Collaborations and suggestions are welcome.

CELINA LERTORA

ENRIQUE SEGURA

Asociación Argentina de Investigadores

Científicos y Tecnológicos,

Solis 453, 1078 Buenos Aires, Argentina

\title{
India's home front
}

SIR - Self-congratulation is not the prerogative of artists. Scientists, especially Indian scientists, are adept at praising themselves, albeit subtly. In Dr Balasubramanian's letter (Nature 307, 312; 1984) the statement that there are "pockets of brilliance" in India, as in any other country, conveniently ignores the embarrassing questions about who is to decide who is brilliant and what constitutes brilliance and gives way to anthropocentricity. It is often forgotten that the greatest "pocket of brilliance" in recent times was not a research institute, but a Swiss patent office. Perhaps the greatest boon of this century is the fact that Albert Einstein was not born in India.

The recent spate of news concerning Indian science and scientists (Nature 304, $300 ; 1983: 4,100,307 ; 1984)$ tends to support Dr Malviya's contention (Nature 306,$10 ; 1983$ ) rather than Dr Balasubramanian's perspective of science in India. On a recent visit to Indian universities and research institutes, I was appalled at the lopsided funding and facilities present there. Glamour in science rather than research relevant to India's needs guides the over-funded institutes. As a scientist Dr Balasubramanian should realize that comparisons of brilliance can be made only when all other variables are constant.

Dr Balasubramanian continues his selfcongratulation in the form of lists (reiteration of what every Indian scientist has been echoing) of accomplishments of Indian scientists. I would not go to the extent of suggesting what some foreign based Indian scientists have been saying: these accomplishments have been made, not because of, but in spite of Indian scientists. Instead of listing the numerous accomplishments, Dr Balasubramanian should have asked "Is this all we have done in the nearly four decades of India's independence?".

I do not agree with everything that $\mathrm{Dr}$ Malviya says about Indian science and scientists. Leaving aside the competence of the people who control scientific circles in India, which Dr Malviya questions, I would like to point out that they, at least, have long enjoyed social position and freedom from criticism. Dr Balasubramanian's appeal to stop selfflagellation is nothing but a plea to maintain the status quo in Indian science. Science, of all human activities, requires criticism to make us aware of anthropocentric prejudice. I therefore applaud $\mathrm{Dr}$ Malviya's attempt at criticism of Indian science and would like to suggest that science governing bodies in India establish an institute and a journal devoted to constructive criticism, where not only scientists but also intelligent taxpayers can debate.

Incidentally, Dr Balasubramanian, pointing out that the issue that carries $\mathrm{Dr}$ Malviya's letter also carries an article by
Indian scientists working in India, neglects to mention that the authors of that paper thank another Indian abroad "for the many gifts that made this study possible".

MANOJ MOJAMDAR

\section{Department of Dermatology,}

Kobe University School of Medicine, Kobe, Japan 650

SIR - The merit of India's science has been the subject of heated discussion in your correspondence columns. It is a healthy sign that such issues are raised now. A few years ago this would not have happened. Something good will eventually come of the polemics and accusations. The focus must, however, be on self-realization, an agonizing reappraisal at that and not indulgence in whipping by "prodigals" (Dr Malviya) or self-aggrandizement by the "natives" (Dr Balasubramanian): the present "natives" were once "prodigals" themselves.

As for the hostility of the natives towards the prodigals, I can confirm from my own experience. A few years ago, when I visited India for a family reunion, I offered to give a couple of seminars in two important institutions in Madras and Bangalore. The chairman of the chemistry department at one of them replied that in view of their hectic institutional activities, he was "unable" to "host" my seminar. He probably thought it was a favour to me and that I might ask for a job in his department! I subsequently gave a seminar in another department in the same institution without ever meeting the chemistry department chairman.

There is also general apathy among higher-ups towards their "subordinates". There seem to be no peers among scientists in India - just power brokers and the rest. A few years ago, a prominent Indian expatriate visited India. One of the top science bureaucrats made arrangements to invite him to his of fice through a back door on the pretext that a lot of others for whom he had no time were waiting to see him at the front door. A lot has to change in the Indian science scene.

Nevertheless, Indian science has made significant progress in the past 35 years. I see good work coming out of the National Chemical Laboratory in Poona in the field of biotechnology, for instance. However, the achievement is minuscule compared with the potential. The myth of India being the third "superpower" in science when one considers the number of scientists and technicians has to be denied. As your correspondent, Vera Rich, observed in a recent report in Nature, the scientific force in India is not as awesome as it is made out to be when one considers the quality. But India has the potential. It has to be properly tapped.

Before the Indian government plunges into any bold venture, such as a "science 
city", it would be well advised to assemble an international commission composed of 20 members to be drawn equally from the four following groups: (1) science leaders in India, (2) prominent Indian expatriate scientists in the United States, (3) leaders of scientific establishments in Europe, and (4) science educators and researchers in the United States. The task should be to make proposals which will improve science education in Indian universities, enhance the research environment in the universities and institutes, and develop support facilities such as manufacturing and servicing state-of-the-art instrumentation. I am sure that scientists from the United States and Europe would be glad to participate in a summer "sabbatical" of this type in the interest of world science.

S. SUBRAMANIAN

Miles Laboratories Inc.,

Elkhart, Indiana 46515, USA

SIR - Although we feel that there is nothing wrong in India's plans to build a technology city (Nature 305, 350; 1983) similar to the Tsukuba science city in Japan, we believe that this would not solve the main problem - India should stop deliberately encouraging its experts to leave the country. We agree with the suggestion (Nature 306, 310; 1983) that in order to encourage intellectuals to remain in India, money must be spent on improving the existing facilities for research. In addition, we suggest that India should make further provisions to send its young and talented scientific staff abroad for advanced training, and provide them with suitable facilities on their return. We understand that many scientists who go abroad are forced to resign their positions at home because of stringent governmental policies. When better conditions for research are available to the many intellectuals who remain in the country, India can stop recalling experts from abroad.

P. BALAKRISHNA MURTHY

Research Institute for Nuclear

Medicine and Biology,

Hiroshima University,

RAMSUNDAR RAM KANAUJIA

Department of Orthopaedic Surgery,

School of Medicine.

Hiroshima University,

1-2-3 Kasumi-cho, Hiroshima 734, Japan

\section{Submarines risky?}

SIR - The proposal to restrict nuclear arsenals to the seas where they can carry out their stated function of deterrence (Nature 23 February, p.680) has much to commend it, but certainly needs additions to cover antisubmarine warfare. Research in this field would have to be prohibited and those systems already established be dismantled, as they threaten to destroy the very invulnerability of submarines on which the whole proposal is based.

47 Conduit Road,

ROBERTWALL

Bedford MK40 IEQ, UK

\section{PWR in haste}

SIR - In his article, "Next reactor still not decided" (Nature 26 January, p.307), your correspondent states that the Central Electricity Generating Board plans to build a pressurized water reactor (PWR) at Sizewell in "a record 19 months".

Would that such miracles could happen. Clearly his figure is a misquote for the 90 months from laying main foundations that CEGB is estimating for investment appraisal purposes for the construction of Sizewell B.

However, this still would not be a record. Our Magnox nuclear stations were in commercial operation in a shorter period, and some US PWRs and may French ones have been built in less than 90 months. Indeed, CEGB also has set itself a construction target of less than 90 months.

The article concludes with a misleadingly pessimistic picture of developments in the project. General inflation has, of course, resulted in costs rising in market price terms. But, so far, there has been no increase in our total estimate of the cost of Sizewell B in real terms (that is, at March 1982 price levels).

Although the length of the public inquiry means that we cannot place main foundations in line with the original timetable, this does not affect the 90 -month construction period. It does, however, mean that the electricity consumer will have to wait longer for the economic benefits CEGB believes that Sizewell B, if approved, would bring.

\section{Economic Adviser,}

P. E. WATTS

Sizewell 'B' Public Inquiry

Central Electricity Generating Board,

PO Box 333, The Maltings,

Snape, Suffolk IPI7 ISP, UK

\section{Not so simple}

SIR - In your issue of 1 December (Nature 306,$418 ; 1983$ ) you reproduced a year-byyear plot of Norwegian tobacco consumption for 1950-1980, presumably intended to support the argument that a ban on cigarette advertising can be effective in limiting the growth of consumption. The graph seems to be open to question on two grounds. One is that the rising trend changes to a decline before the year (1975) when the act banning cigarette advertising came into force. The other is the implication that the almost linear increase in consumption between 1950 and 1970 was caused by advertising. It would be prudent here to investigate the role of obvious economic variables such as prices and incomes. I have no data on tobacco prices in Norway, but a rough replotting of per capita tobacco consumption against per capita income at constant prices shows that the ratio between them had been declining since 1950 , and against this background the further decline since 1970 looks much less striking. Such questions should be investi- gated by standard econometric techniques before policy conclusions are drawn from prima facie correlations. The case for discouraging tobacco consumption on health grounds can only be weakened by opportunistic use of incomplete statistics.

Evaluation and Planning Centre,

G. E. CUMPER

London School of Hygiene and

Tropical Medicine,

Gower St, London WCI, UK

\section{Paid referees}

SIR - A recent letter (Nature 2 February, p.408) drew attention to page charges in journals and suggested a possible credit system for referees. However, according to an advertising circular recently received by me, at least one new journal (Engineering Computations) is adopting a "rigorous, remunerated reviewing policy". Apparent$l y$, this is in the hope that payment to referees will minimize the time taken to review the manuscript, thus ensuring rapid publication. I feel that this is a false premise on two counts. First, an examination of the received, revised and publication dates of many papers reveals that the delay between acceptance of a manuscript and publication is often longer than the time between submission and acceptance, which includes the time taken by the author to revise the manuscript. Second, journals, including Nature, achieve rapid publication without resort to payment of referees.

The adoption of remunerated reviewing policy by any journal can only be a retrograde step which may be interpreted by some people as further evidence of scientific integrity being sacrificed by financial gain. Also, it can only further increase the financial load imposed on individual scientists and libraries. Let us hope that the day never comes when a person can state his or her occupation as "professional journal referee'!

\section{Department of Applied Mathematics \\ and Theoretical Physics, \\ University of Cambridge, \\ Silver Street, Cambridge CB3 9EW, UK}

\section{Laughing matter}

SIR - I am compiling an anthology, "Science with a Smile", and should welcome contributions of humour in the sciences: physics, chemistry, astronomy, mathematics, earth sciences, life sciences, and computer science - historic and contemporary. Appropriate would be anecdotes, biographical notes, cartoons, parodies, verse, examples of self-deception and hoaxes. I especially seek pieces which, while humorous, also have value in the history of science, providing insight into changing attitudes and personalities.

ROBERT L. WEBER

104 Davey Laboratory,

University Park,

Pennsylvania 16802, USA 